\title{
Richard de Fournival et les sciences au XIII siècle, textes réunis par Joëlle Ducos et Christopher LUCKEN
}

\section{G. Matteo Roccati}

\section{OpenEdition}

Journals

\section{Édition électronique}

URL : https://journals.openedition.org/studifrancesi/16194

DOI : 10.4000/studifrancesi. 16194

ISSN : 2421-5856

\section{Éditeur}

Rosenberg \& Sellier

\section{Édition imprimée}

Date de publication : 1 juillet 2019

Pagination : 137

ISSN : 0039-2944

\section{Référence électronique}

G. Matteo Roccati, «Richard de Fournival et les sciences au xII ${ }^{e}$ siècle, textes réunis par Joëlle Ducos et Christopher LuCKEN », Studi Francesi [En ligne], 187 (LXIII | I) | 2019, mis en ligne le 01 juillet 2019, consulté le 09 novembre 2021. URL : http://journals.openedition.org/studifrancesi/16194; DOI : https://doi.org/10.4000/studifrancesi.16194

Ce document a été généré automatiquement le 9 novembre 2021.

\section{(c) (i) (9)}

Studi Francesi è distribuita con Licenza Creative Commons Attribuzione - Non commerciale - Non opere derivate 4.0 Internazionale. 


\title{
Richard de Fournival et les sciences au XIII ${ }^{e}$ siècle, textes réunis par Joëlle DUCOS et Christopher LUCKEN
}

\author{
G. Matteo Roccati
}

\section{RÉFÉRENCE}

Richard de Fournival et les sciences au XIII ${ }^{e}$ siècle, textes réunis par Joëlle Ducos et Christopher LUCKEN, Firenze, sismel - Edizioni del Galluzzo, 2018, «Micrologus Library» $88,444 \mathrm{pp}$.

1 Les contributions réunies dans ce recueil sont issues d'un colloque qui s'est tenu à Paris en 2015. L'article introductif - Christopher LUCKEN, Parcours et portrait d'un homme de savoir, pp. 3-45 - rassemble ce que nous connaissons sur la formation et la vie de Richard de Fournival, présente son œuvre, en particulier la Biblionomia, et le contexte amiénois, culturel et technique, dans lequel elle s'insère. Les contributions qui suivent portent en particulier sur la Biblionomia et la classification des savoirs dont elle témoigne (Jean-Marc MANDOSIO, La «Biblionomia» de Richard de Fournival et la classification des savoirs au XIIIe

siècleDRAELANTSLa «Biblionomia» de Richard de Fournival, une bibliothèque d'encyclopédiste? Enquête comparative sur les textes et les manuscrits

2 Artithmétique et géométrie: Marc MoYon, Arithmétiques et géométries au XIIIe siècle d'après la «Biblionomia»: des traductions arabo-latines à Jordanus de NemoremioloScience des nombres, science des formes: arithmétique et géométrie dans les manuscrits de la «Biblionomia» de Richard de Fournival

3 Médecine: Monica H. GREEN, Richard de Fournival and the Reconfiguration of Learned Medicine in the Mid-13 ${ }^{\text {th }}$ Century, pp. 179-206; Laurence MOULINIER-BROGI, Richard de Fournival, la «Biblionomia» et la science des urines, pp. 207-226; Martina GIESE, Works on 
Horse Medicine in the "Biblionomia» of Richard de Fournival in the Context of the High Medieval Tradition, pp. 227-241.

4 Alchimie: Antoine CALVET, Le «De arte alchemica» (inc.: Dixit Arturus explicator huius operis) est-il une cuvre authentique de Richard de Fournival?, pp. 243-282; édition provisoire et traduction du texte aux pp. 260-282.

5 Astrologie: Jean-Patrice BOUDET - Christopher LUCKEN, In Search of an Astrological Identity Chart: Richard de Fournival's «Nativitas», pp. 283-322; Nicolas WEILL-PAROT, La «Biblionomia» de Richard de Fournival, le «Speculum astronomiae» et le secret, pp. 323-338; Charles BURNETT, Richard de Fournival and the «Speculum astronomiae», pp. 339-348.

6 Le De vetula, dont l'attribution à Richard de Fournival reste douteuse pour la plupart des critiques, fait l'objet des deux derniers articles: Marie-Madeleine HUCHET, Le «quadrivium» dans le «De vetula» attribué à Richard de Fournival, pp. 349-361; Cecilia PANTI, An Astrological Path to Wisdom. Richard de Fournival, Roger Bacon and the Attribution of the Pseudo-Ovidian «De vetula», pp. 363-400.

7 Conclusion par Joëlle Ducos, pp. 401-408; index des noms, locorum, rerum, des manuscrits, pp. 411-443. 